\title{
SEMERBAK HARUM SANG KUSUMA: WADAH PELESTARIAN SENI DAN BUDAYA SUKU TENGGER DI PUNCAK BROMO
}

\author{
Junita Delphin ${ }^{1)}$, Sutarki Sutisna ${ }^{2)}$ \\ 1)Program Studi S1 Arsitektur, Fakultas Teknik, Universitas Tarumanagara, junitadelphin31@gmail.com \\ 2) Program Studi S1 Arsitektur, Fakultas Teknik, Universitas Tarumanagara, sutarkis@gmail.com
}

\begin{abstract}
Abstrak
Suku Tengger merupakan suku asli yang tinggal di area sekitar Gunung Bromo yang juga terikat secara budaya dan tradisi. Suku Tengger memiliki kepercayaan bahwa Gunung Bromo adalah tempat para dewa dan leluhur mereka tinggal sehingga kepercayaan ini yang menjadi pedoman mereka dalam menjaga dan menghormati alam sekitar Gunung bromo. Namun dengan adanya tantangan globalisasi yang terus maju dan adanya wisatawan yang terus berdatangan setelah Gunung Bromo dijadikan destinasi wisata, budaya dan tradisi asli Suku Tengger semakin terpengaruh modernisasi dan perlahan-lahan mulai luntur. Lunturnya budaya ini dikhawatirkan akan menurunkan semangat Suku Tengger dalam menjaga dan menghormati alam yang menjadi pedoman dalam budaya mereka. Metode yang digunakan adalah dengan penerapan beberapa langkah seperti data lokasi, analisis tapak, analisis program, serta konsep dan metode desain untuk menghasilkan gagasan baru dalam menjawab persoalan yang dihadapi Suku Tengger. Kesimpulan berupa wadah pelestarian seni dan budaya dengan tujuan untuk mempertahankan budaya tradisional sekaligus menjawab tantangan modernisasi melalui pemakaian teknologi sehingga tercapai keharmonisan antar kedua budaya untuk Suku Tengger khususnya untuk generasi muda dan membentuk suatu ekologi yang seimbang. Dengan pendekatan Regionalisme Kritis dan penerapan puisi Kidung Tengger yang diterjemahkan kedalam enam skema, dihasilkan arsitektur dengan unsur arsitektur Majapahit dan didukung dengan unsur alam seperti matahari, air, bunga, kabut, hujan, serta bebatuan pegunungan. Kegiatan-kegiatan yang berhubungan dengan ciri khas Suku Tengger seperti kerajinan sarung, taman bunga Edelweis, plataran, pemadian air panas, dan ruang memori Suku Tengger juga dihadirkan.
\end{abstract}

\section{Kata kunci: Gunung Bromo; Pelestarian Budaya; Regionalisme Kritis; Suku Tengger}

\section{Abstract}

The Tengger tribe is an indigenous tribe that lives in the area around Mount Bromo, bound by culture and tradition. The Tengger tribe have a belief that Mount Bromo is the place where the gods and their ancestors live, so this belief becomes their guide in protecting and respecting the nature around Mount Bromo. However, with the challenges of globalization that continue to advance and Mount Bromo has become a tourist destination, the indigenous culture and traditions of the Tengger tribe are increasingly affected by modernization and are slowly fading away. It is feared that this cultural fading will reduce the spirit of the Tengger tribe in protecting and respecting nature which is the cores in their culture. The method used in the application of several steps such as location data, site analysis, program analysis, design concept and methods, to produce new ideas in answering the problems faced by the Tengger tribe. The conclusion is a place for art and culture preservation to maintain traditional culture as well as respond to the challenges of modernization through the use of technology to achieve harmony between the two cultures for the Tengger tribe, especially for the future generations. With a Critical Regionalism approach and the application of the Kidung Tengger peom which was translated into six schemes and combined with elements of Majapahit architecture by strengthening natural elements such as sun, water, flower, fog, rain, and mountain rocks. The program related to the characteristics of the Tengger tribe such as sarong crafts, Edelweis flower garden, platforms, bathhouse, and Tengger tribe memory room are also presented.

Keywords: Critical Regionalism; Cultural Preservation; Mount Bromo; Tengger Tribe

\section{PENDAHULUAN Latar Belakang}

Suku Tengger merupakan suku yang mendiami kawasan disekitar Gunung Bromo dan memiliki 
tradisi yang unik. Masyarakat Suku Tengger selalu melestarikan dan menjaga alam Gunung Bromo melalui budaya dan tradisi mereka. Salah satunya dengan perayaan upacara Yadnya Kasada yang rutin digelar setiap tahun sebagai upacara utama dalam rangka mengucap pujian akan alam yang indah serta memberikan sesajen sebagai bukti bahwa bumi yang diberikan kepada mereka tetap dilestarikan. Gunung Bromo merupakan destinasi wisata alam yang terkenal di Jawa Timur dimana menarik banyak wisatawan setiap tahunnya. Semenjak dibuka pada tahun 1982, Gunung Bromo mulai banyak didatangi masyarakat luar yang mulai mengubah dinamika masyarakat Suku Tengger. Dapat dilihat pada tabel 1, dari tahun ke tahun jumlah wisatawan di Gunung Bromo terus meningkat dan dapat diprediksi akan terus mengalami peningkatan di tahun berikutnya.

Tabel 1. Daftar Pengunjung Taman Nasional Bromo Tengger Semeru (TNBTS)

\begin{tabular}{cccc}
\hline Tahun & $\begin{array}{c}\text { Wisatawan } \\
\text { Domestik (Orang) }\end{array}$ & $\begin{array}{c}\text { Wisatawan } \\
\text { Mancanegara(Orang) }\end{array}$ & Jumlah (Orang) \\
\hline 2008 & 42.367 & 8.893 & 52.260 \\
\hline 2009 & 81.838 & 11.287 & 93.125 \\
\hline 2010 & 84.566 & 14.551 & 99.117 \\
\hline 2011 & 58.319 & 12.652 & 70.971 \\
\hline 2012 & 152.809 & 16.803 & 169.612 \\
\hline 2013 & 235.327 & 18.376 & 253.703 \\
\hline Jumlah & 651.521 & 82.562 & 738.788 \\
\hline
\end{tabular}

Sumber: Data Pengunjung "Resort Tengger Laut Pasir" dalam angka, 2013

Wisatawan tentunya membawa dampak positif seperti membantu meningkatkan ekonomi Suku Tengger. Namun dengan banyaknya wisatawan yang berkunjung, nyatanya budaya modern yang dibawa oleh wisatawan yang dinamis, dapat mempengaruh perilaku dan pola pikir Suku Tengger yang statis terhadap budaya dan tradisi yang dipegang selama ini. Pertentangan budaya ini paling dirasakan oleh generasi muda Suku Tengger yang mulai hidup berdampingan dengan pengaruh yang dibawa wisatawan.

\section{Rumusan Masalah}

Suku Tengger perlahan-lahan mengalami perubahan dalam tradisi dan budayanya akibat tantangan globalisasi dan pengaruh budaya modern yang dibawa wisatawan. Banyak dari masyarakat Suku Tengger yang tidak lagi mengikuti upacara-upacara kebudayaan dan didukung fakta bahwa generasi muda Suku Tengger yang semakin banyak migrasi ke kota. Melunturnya budaya Suku Tengger ini dikhawatirkan akan menyebabkan menurunnya pelestarian akan Gunung Bromo akibat menurunnya kepercayaan terhadap pandangan akan Gunung Bromo sebagai sumber kehidupan Suku Tengger secara budaya dan tradisi.

\section{Tujuan}

Proyek ini adalah wadah yang menampilkan unsur-unsur kebudayaan Suku Tengger untuk mempertahankan sekaligus membangun kegiatan yang menjadi pegangan kuat dalam melestarikan budaya dan tradisi Suku Tengger. Tujuannya adalah untuk menghadirkan kembali memori dan memperkuat budaya dalam menjaga keharmonisan antara budaya tradisional dan modern sehingga tercipta keseimbangan ekologi masa depan untuk kebaikan dan kehidupan Suku Tengger khususnya bagi generasi muda.

\section{KAJIAN LITERATUR}

\section{Gunung Bromo}

Gunung Bromo merupakan gunung berapi aktif yang terletak di Jawa Timur, Indonesia. Gunung Bromo memiliki ketinggian 2.329 meter diatas permukaan laut dan berada di perbatasan empat wilayah kabupaten yaitu Kabupaten Probolinggo, Kabupaten Lumajang, Kabupaten Pasuruan, 
dan Kabupaten Malang. Gunung Bromo termasuk dalam wilayah Taman Nasional Bromo Tengger Semeru (TMBTS) seluas 50.267 ha yang terdiri dari wisata Gunung Bromo, Gunung Semeru, Lautan Pasir, dan Danau Ranu Kumbolo. Taman nasional yang didirikan pada tahun 1982 ini, merupakan tempat berbagai ekosistem flora dan fauna yang beragam termasuk 1.025 jenis flora dan 38 jenis satwa liar, 118 jenis burung, 18 mamalia, serta 11 spesies reptil. Bentuk Gunung Bromo saling berhubungan antara lembah dan ngarai dengan kaldera berisi lautan pasir seluas $10 \mathrm{~km}$. Gunung Bromo berasal dari bahasa sansekerta yaitu Brahma yang merupakan seorang dewa utama Hindu. Hal ini yang menunjukkan Gunung Bromo memiliki keterikatan dengan kepercayaan terlebih dengan yang dianut oleh masyarakat sekitarnya. Gunung Bromo memiliki curah hujan $2000 \mathrm{~m} /$ tahun dan suhu rata-rata harian $10^{\circ}-20^{\circ} \mathrm{C}$. Pada musim hujan, terjadi kelembapan udara rata-rata $80 \%$, suhu berubah tergantung ketinggian, antara $3^{\circ}-8^{\circ} \mathrm{C}$ (Putra, 2018).

\section{Suku Tengger}

Suku Tengger adalah suku asli yang bermukim di sekitar area dan lereng Gunung Bromo. Populasi Suku Tengger berjumlah \pm 23.000 jiwa yang tersebar di beberapa desa seperti desa Ngadas, Jetak, Wontoro, Ngadijero, Ngadisari, Tosari, Ledokombo, Pandansari, Wonokerso, Sedaeng, Ngadiwono, dan Argosari. Suku Tengger memiliki mayoritas mata pencaharian sebagai petani, sekitar 95\% dan 5\% sebagai pegawai negeri, buruh, pedagang, dan usaha jasa. Bidang jasa antara lain berhubungan dengan wisatawan seperti menyewakan kuda atau mobil jeep dan menyediakan sewa tempat tinggal karena daerah Gunung Bromo yang merupakan destinasi wisata (Hikmah, Sazhiyah, \& Sulistyowati, 2020). Mayoritas masyarakat Suku Tengger beragama Hindu dan diceritakan sebagai orang-orang keturunan kerajaan Majapahit (Haliim, 2018).

Suku Tengger merupakan suku yang masih memiliki kepercayaan kepada legenda dan tradisi masyarakatnya terutama penghormatan pada leluhur mereka yaitu Jaka Seger, Rara Anteng dan Raden Kusuma. Nama Tengger sendiri dipercayai berasal dari kata "Teng" yaitu Rara Anteng dan "Ger" yaitu Jaka Seger. Suku yang disebut juga sebagai "orang gunung" ini mempunyai ciri khas memakai sarung dan menunggang kuda. Disetiap halaman rumah mereka banyak ditanami Bunga Edelweis sebagai bentuk budidaya terhadap bunga khas dataran tinggi tersebut.

\section{Legenda Raden Kusuma dan Upacara Yadnya Kasada}

Suku Tengger selalu hidup dengan memiliki kepercayaan terhadap legenda Raden Kusuma yang diceritakan sebagai leluhur mereka. Legenda dimulai dari cerita kehidupan Rara Anteng dan Jaka Seger yang mendambakan keturunan setelah pernikahan, namun tidak juga mendapatkan keturunan. Rara Anteng dan Jaka Seger pun bertapa di Gunung Bromo sebagai tempat tinggal Sang Hyang Widhi. Suatu ketika, Sang Hyang Widhi memberikan mereka keturunan dengan syarat salah seorang anak dijadikan korban persembahan ke kawah Gunung Bromo. Selang beberapa waktu, Rara Anteng dan Jaka Seger pun dikaruniai 25 anak dan anak paling bungsu diberi nama Raden Kusuma. Hingga Raden Kusuma berumur 10 tahun, Jaka Seger dan Rara Anteng tidak kunjung menepati janjinya ke Gunung Bromo dan menyembunyikan anak-anaknya di gunung Penanjakan. Namun Gunung Bromo terus meletus hingga merusak lingkungan sekitarnya dan menakuti masyarakat Suku Tengger lainnya. Raden Kusuma yang mengetahui hal tersebut pun mengorbankan dirinya sendiri ke kawah Gunung Bromo demi keselamatan Suku Tengger. Raden Kusuma juga meminta setiap tanggal 14 bulan Kasada, Suku Tengger mengirimkannya beragam hasil ladang sebagai persembahan untuknya. Upacara persembahan tersebut menjadi tradisi yang diselenggarkan secara turun temurun hingga saat ini yang diberi nama Yadnya Kasada (Adam \& Liana, 2020).

\section{Budaya}

Budaya dapat diartikan sebagai "Pikiran dan akal", yang mengandung pengetahuan, kesenian, kepercayaan, moral, hukum, adat istiadat, dan unsur lainnya sebagai seorang anggota 
masyarakat. (Koetjaraningrat, 2005). Budaya juga merupakan cara atau sikap hidup manusia yang mempunyai hubungan timbal balik dengan alam lingkungan hidupnya yang mengandung hasil dari cipta, karya, baik secara fisik materi maupun spiritual. Demikian kebudayaan mencakup pola-pola perilaku, berpikir, dan cara-cara lainnya (Ranjabar, 2006).

\section{Regionalisme Kritis}

Regionalisme Kritis adalah pendekatan arsitektur yang muncul sebagai tanggapan dari aliran modernisme, yang berusaha menggunakan prinsip modern tetapi berasal dari lokalitas. Regionalisme kritis adalah sebuah bentuk sindiran untuk melawan modernisme dan tetap berusaha meneruskan tradisi dan lokalitas. Frampton mengemukakan bahwa regionalisme kritis lebih menekankan pada kualitas tempat (dengan unsur genius loci) dari pada ruang (yang dapat ditempatkan dimana saja) (Gambar 1) (Frampton, 1983). Berdasarkan uraian yang dikemukakan, sebuah arsitektur dapat dianggap sebagai arsitektur Regionalisme Kritis jika menerapkan; 1) Memiliki kualitas arsitektur modern tetapi masih menerapkan kelokalitas tempat; 2) Bangunan mengikuti kondisi topografi tapak; 3) Memaksimalkan cahaya alami yang masuk; 4) Mengolah elemen lokal dalam bangunan; 5) Memanfaatkan perkembangan teknologi sesuai zamannya.

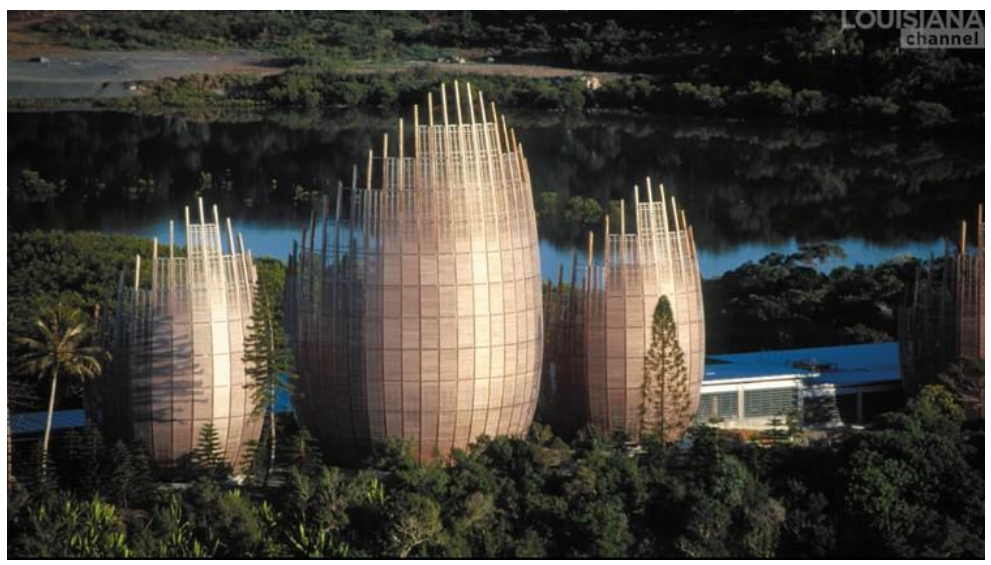

Gambar 1. Jean-Marie Tjibaou Cultural Center by Renzo Piano

Menekankan pengaruh lokalitas yaitu terinspirasi dari orang Kanak dengan keterampilan membangunnya tetapi juga dengan perpaduan modern yaitu penggunaan material modern seperti kaca, aluminium, dan baja.

Sumber: Archdaily, 2018

\section{METODE}

Dalam mempersiapkan rancangan desain, data pendukung awal didapatkan dengan menggunakan metode pengumpulan data berupa jurnal-jurnal illmiah beserta $e$-book dan video pendukung. Data pendukung berupa informasi seputar Gunung Bromo, Suku Tengger dan kebudayaannya, beberapa teori yang mendukung seperti teori tentang budaya dan Regionalisme Kritis. Semua data yang diolah berupa data sekunder.

Dalam tahapan penelitian desain, beberapa langkah yang digunakan untuk menghasilkan rancangan antara lain; 1) Data lokasi; 2) Analisis tapak; 3) Analisis program; 4) Konsep dan metode desain.

a. Data Lokasi, Memahami lokasi tapak beserta lingkungannya. Mencari data-data statistik seperti ketinggian, data geografi, serta titik-titik penting disekitar lokasi tapak.

b. Analisis Tapak, Setelah memahami lokasi tapak dan lingkungannya, dilakukan analisis tapak seperti lingkungan, akses, aksis, angin, matahari, arah pandang baik kedalam maupun keluar tapak, dan kontur dengan metode pengumpulan data dari jurnal maupun google maps.

c. Analisis Program, Untuk menentukan program, digunakan metode Critical Regionalism (Regionalisme Kritis) yang mengacu pada teori menurut William Lim dan Tan Hock Beng 
(Prayogi \& Danial, 2016), ada empat strategi untuk menghasilkan arsitektur dalam regionalisme kritis yaitu:

- Reinvigorating Tradition, membangkitkan bahasa sehari-hari dengan cara menghidupkan kembali kearifan kerajinan tradisional yang asli.

- Reinventing Tradition, mencari suatu paradigma baru dan menghasilkan sesuatu yang berkelanjutan.

- Extending Tradition, penggunaan teknologi untuk memodifikasi suatu tradisional.

- Reinterpreting Tradition, penggunaan kontemporer untuk mengubah keformalan tradisional dengan cara yang lebih menyegarkan.

d. Konsep dan Metode Desain, konsep perancangan menerapkan konsep yang berhubungan dengan persoalan yang diambil dan sesuai tema perancangan yaitu beyond ecology. Metode desain yang digunakan untuk perancangan diambil dari puisi asli Suku Tengger. Hasil dari penerapan konsep digabungkan dengan hasil dari sintesis tapak yang akan menghasilkan gubahan massa.

Dari keseluruhan metode tersebut dihasilkan sebuah produk arsitektur dimana gambaran keseluruhan proyek merupakan gambaran kehidupan masyarakat Suku Tengger yang hidup dengan keharmonisan kedua budaya yang tersatukan dalam konsep ekologi masa depan untuk kehidupan yang dijalankan Suku Tengger.

\section{DISKUSI DAN HASIL}

\section{Data Lokasi}

Lokasi terletak di Gunung Penanjakan arah utara Gunung Bromo, Kecamatan Tosari, Kabupaten Pasuruan, Jawa Timur dengan luas tapak 4,5 Ha. Lokasi berada di ketinggian 2.782 diatas permukaan laut. Karena terletak pada area kawasan destinasi wisata, beberapa titik lokasi penting yang berada di sekitar tapak yaitu kawah Gunung Bromo, Gunung Batok, Pasir Berbisik, Gunung Widodaren, Bukit Teletubies, Gunung Penanjakan, Air Terjun Widodaren, Hutan Edelweis, beberapa viewpoint dari Gunung Penanjakan seperti Seruni Point, Bukit Kingkong, viewpoint Penanjakan, dan Bukit Cinta (Gambar 2). Pemilihan lokasi terletak pada jalur penghubung antar desa dan jalur pendakian wisatawan. Dalam cerita Raden Kusuma, Gunung Penanjakan juga disebutkan sebagi tempat Rara Anteng dan Jaka Seger menyembunyikan anakanaknya dari letusan Gunung Bromo. Menurut data Pusat Vulkanologi, Mitigasi Bencana Geologi (PVMBG), lokasi ini juga termasuk dalam kawasan rawan bencana I yang rentan akan hujan abu saat Gunung Bromo erupsi (BP86, 2010). Pencapaian tapak dapat dilalui pejalan kaki, menunggang kuda maupun mobil jeep.

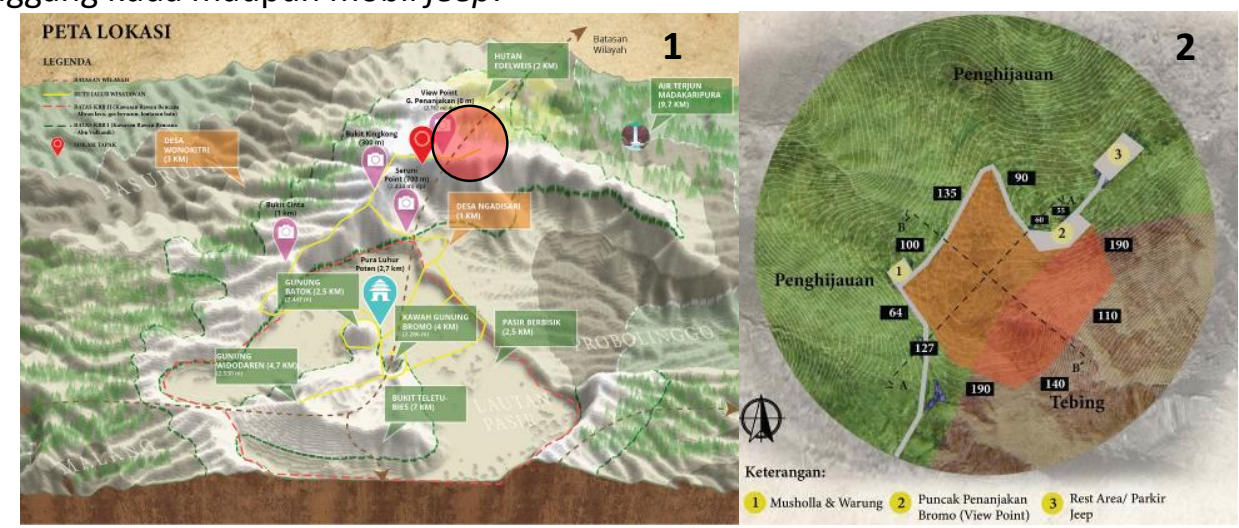

Gambar 2. (1) Peta lokasi, lokasi berada di gunung penanjakan arah utara Gunung Bromo;

(2) Data tapak, ukuran dan kondisi eksisting tapak.

Sumber: Penulis, 2021

Lokasi tapak berada di area tebing dan memiliki dua kondisi tanah yaitu area penghijauan dan bebatuan. Tapak dilalui jalur dua arah dan berbatasan dengan musholla, parkir, dan viewpoint 
penanjakan (Gambar 2). Tidak ada peraturan khusus yang ditetapkan untuk pembangunan di area ini.

Keunggulan lokasi tapak terpilih dengan alasan sebagai berikut:

- Mendapat pemandangan ke Gunung Bromo dari area tertinggi dengan pemandangan jelas untuk matahari terbit dan matahari terbenam.

- Mendapat aksis satu garis dengan Gunung Bromo dan Gunung Semeru untuk memenuhi aspek budaya.

- Daerah rute yang dilewati masyarakat Suku Tengger untuk penghubung antar desa maupun jalur penanjakan wisatawan.

- Berbatasan langsung dengan viewpoint Gunung Penanjakan sebagai tempat untuk memandangi matahari terbit.

- Berada pada area yang dekat dengan dilakukannya upacara Yadnya Kasada. Proses upacara dilakukan dari desa Ngadisari menuju lautan pasir dan Gunung Bromo. Jalur yang dilewati Suku Tengger untuk mengikuti upacara Yadnya Kasada melalui lokasi tapak.

\section{Analisis Tapak}

Setelah mendapatkan informasi dari data lokasi, dilakukan analisis tapak untuk selanjutnya dihasilkan sintesis rancangan. Dalam proses analisis tapak (Gambar 3), ditetapkan delapan aspek utama dalam menganalisis tapak yaitu: 1) Kondisi lingkungan eksisting; 2) Akses; 3) Aksis; 4) Arah Angin; 5) Matahari; 6) Arah pandang kedalam tapak; 7) Arah pandang keluar tapak; 8) Kontur.

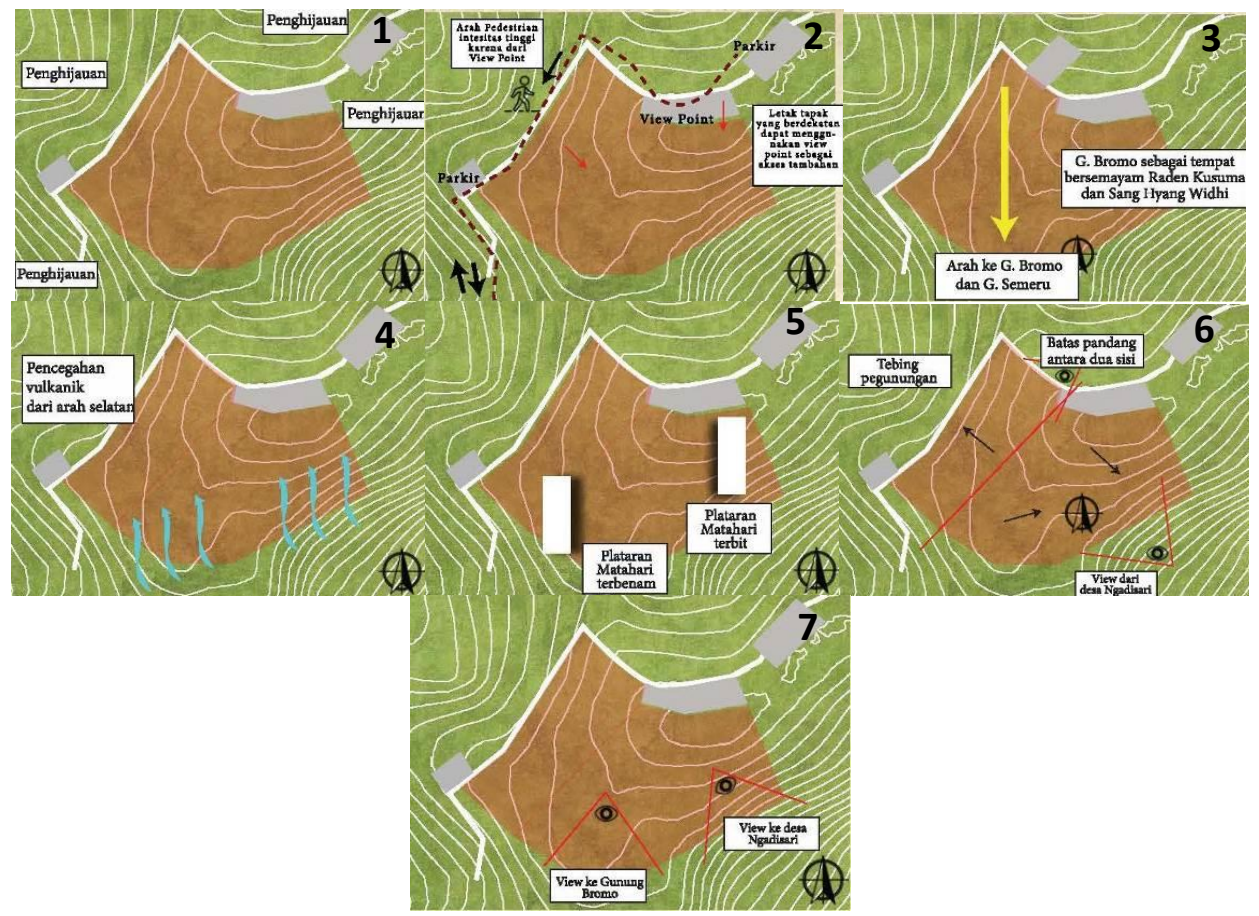

Gambar 3. (1) Kondisi lingkungan eksisting; (2) Akses; (3) Aksis; (4) Arah abu vulkanik; (5) Matahari; (6) Arah pandang kedalam tapak; (7) Arah pandang keluar tapak Sumber: Penulis, 2021

1) Kondisi lingkungan eksisting, tapak dikelilingi oleh kondisi tanah berupa penghijauan dan bebatuan alami pegunungan serta kondisi lahan yang berkontur dengan kemiringan di tiap sisi yang berbeda.

2) Akses, tapak berdekatan dengan lokasi viewpoint penanjakan yang dapat digunakan sebagai akses serta arah jalan dua arah dengan tersedia parkir di depan tapak. 
3) Aksis, dengan menerapkan unsur budaya Majapahit yaitu aksis ke gunung sebagai tempat bersemayam Sang Hyang Widhi, arah bangunan dapat menghadap ke arah aksis Gunung Bromo dan Gunung Semeru yang disesuaikan dengan kondisi kontur tapak.

4) Arah angin, yaitu memperhatikan arah datang abu vulkanik saat Gunung Bromo erupsi dari arah selatan tapak.

5) Matahari, sebagai unsur atraktif dalam tapak dapat dimanfaatkan titiknya untuk dijadikan tempat untuk memandang matahari terbit maupun terbenam sebagai nilai tambah untuk wisatawan.

6) Arah pandang kedalam tapak, kondisi tapak yang berkontur membatas secara alami arah pandang dari sisi luar kedalam, dari arah selatan dapat terlihat dengan jelas kondisi tebing, sedangkan arah utara hanya dapat melihat kondisi penghijauan yang sedikit landai.

7) Arah pandang keluar tapak, kondisi tebing tapak dan posisi yang tinggi dapat melihat keseluruhan pemandangan lingkungan Gunung Bromo, Gunung Semeru, dan desa-desa disekeliling.

8) Kontur, mengidentifikasi arah dan derajat kemiringan kontur pada masing-masing bagian tapak untuk menetapkan bentuk bangunan yang sesuai (Gambar 4).

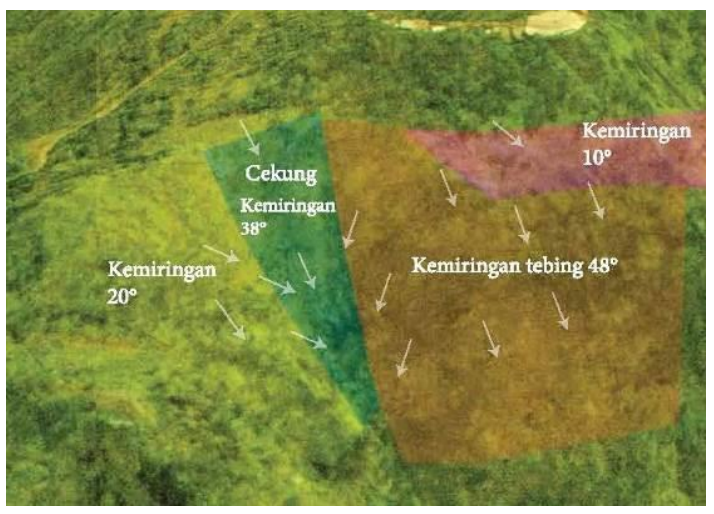

Gambar 4. Kemiringan kontur tapak

Sumber: Penulis, 2021

Dari hasil analisis tapak, dihasilkan sintesis untuk rencana awal rancangan yaitu kondisi kontur tanah yang cekung dialiri air dan dihubungkan dengan jembatan, sedangkan kondisi tanah ditebing dengan miring $20^{\circ}$ dan $48^{\circ}$ dapat dibuat ruang dalam tanah, kondisi tanah yang sedikit landai (kemiringan $10^{\circ}$ dan $20^{\circ}$ ) digunakan untuk plataran (Gambar 4). Titik yang dibuat plataran dengan arah hadap timur dan barat dapat digunakan untuk memandangi matahari terbit maupun terbenam. Akses masuk dapat dihubungkan dengan viewpoint penanjakan melalui lift tambahan sedangkan akses lainnya berada dekat dengan area parkir eksisting. Bunga Edelweis ditanami dibagian area penghijauan.

\section{Analisis Program}

Melalui metode Regionalisme Kritis sebagai metode pembentukan program, tidak hanya berusaha untuk mempertahankan budaya namun sekaligus menerima modernisasi dalam hal ini dapat digabungkan dengan pemakaian teknologi. Melalui strategi menurut William Lim dan Tan Hock Ben, maka dihasilkan program yaitu:

1) Reinvigorating Tradition - Sarung Tenun dan kerajinan Bunga Edelweis. Sarung tenun memiliki arti bagi Suku Tengger tidak hanya untuk menghangatkan tubuh tetapi juga sebagai penghormatan pada warisan leluhur. Sarung digunakan sebagai tanda status pernikahan seorang wanita. Tidak hanya sarung, bunga Edelweis juga menjadi ciri khas Suku Tengger karena menjadi bunga yang dilindungi di Gunung Bromo. Budidaya Edelweis dapat dijadikan kerajinan untuk selebihnya dijual kepada wisatawan. 
2) Reinventing Tradition - Plataran. Suku Tengger selalu mengadakan upacara-upacara adat yang dilaksanakan bersama dengan sesama masyarakat Suku Tengger baik untuk melakukan tarian, pembacaan kidung, maupun nyanyi-nyanyian. Plataran dapat menjadi wadah Suku Tengger agar selalu melaksanakan budaya tersebut. Plataran juga menjadi wadah untuk wisatawan dapat memandang Gunung Bromo dan matahari terbit maupun terbenam.

3) Extending Tradition - Pemanfaatan Geothermal. Gunung Bromo adalah gunung berapi aktif yang memiliki sumber energi panas bumi yang dapat dimanfaatkan. Untuk memanfaatkan energi ini dan dikombinasikan dengan budaya maka dapat digunakan untuk pemandian air panas.

4) Reinterpreting Tradition- Ruang memori Suku Tengger. Seluruh memori dan sejarah tentang cikal bakal perjalanan Suku Tengger, cerita kehidupan Jaka Seger, Rara Anteng, dan Raden Kusuma diringkas dan dihadirkan dalam bentuk relief dan monumen yang dapat dinikmati pengunjung.

Melalui empat strategi tersebut maka dihasilkan program yaitu:

1) Kerajinan sarung tenun, kerajinan sarung dilakukan oleh Suku Tengger yang dapat diperjual belikan kepada wisatawan;

2) Budidaya taman bunga Edelweis, hasil budidayanya dapat diperjual belikan;

3) Plataran Upacara untuk melakukan upacara maupun acara budaya;

4) Plataran Edelweis untuk pengunjung dapat menikmati bunga edelweis;

5) Plataran Bromo dan matahari tebit untuk memandang alam;

6) Ruang memori Suku Tengger untuk menampilkan relief perjalanan Suku Tengger.

\section{Konsep dan Metode Desain}

Konsep utama dalam rancangan adalah mengadaptasi cerita Raden Kusuma dimana menjadi kepercayaan utama bagi Suku Tengger. Dinamakan semerbak harum tidak hanya merepresentasikan harum dari bunga Edelweis namun juga keharmonisan budaya yang perlu dijaga sehingga budaya tradisional dan modern tetap seimbang. Dengan mengadopsi cerita Raden Kusuma, hadirnya proyek ini sebagai pengingat dan identitas Suku Tengger untuk terus sadar akan budaya mereka walaupun pengaruh modernisasi yang dibawa oleh wisatawan terus berdatangan. Perancangan juga menerapkan beberapa ornamen dan konsep arsitektur dari arsitektur Majapahit dimana kerajaan Majapahit sendiri dihubungkan dengan keturunan asli Suku Tengger. Beberapa unsur Majapahit yang diterapkan antara lain penerapan Candi Wringin Lawang, Candi Bajang Ratu, dan Candi Surowono, konsep plataran sebagai awal dan akhir disetiap area dan dihubungkan dengan plataran, dan ornamen serta penebalan dinding bata (Gambar 5). Tidak hanya diterapkan pada bagian fasad bangunan tetapi juga pada bagian dalam seperti penerapan suasana majapahit pada pemandian air panas.

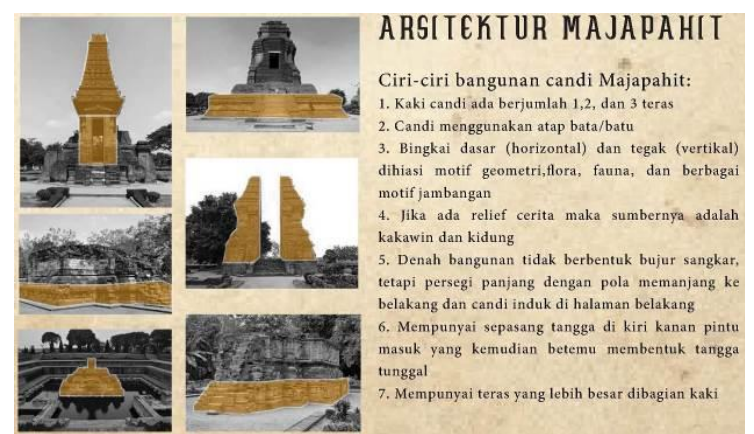

1

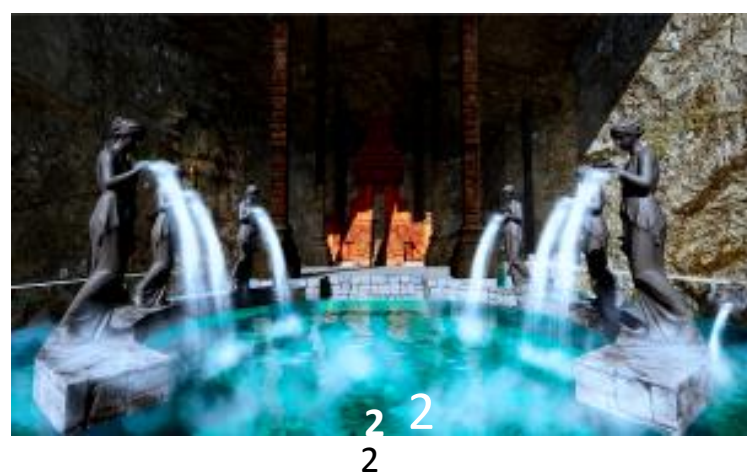

2

Gambar 5. (1) Tipologi dan ciri-ciri arsitektur Majapahit; (2) Suasana pemandian air panas Sumber: Penulis, 2021 
Metode yang digunakan dalam perancangan adalah dengan mengadopsi cerita Raden Kusuma melalui puisi Kidung Tengger (Gambar 6). Puisi ini dibacakan disetiap acara upacara Yadnya Kasada sebagai bentuk penghormatan Suku Tengger terhadap Raden Kusuma.

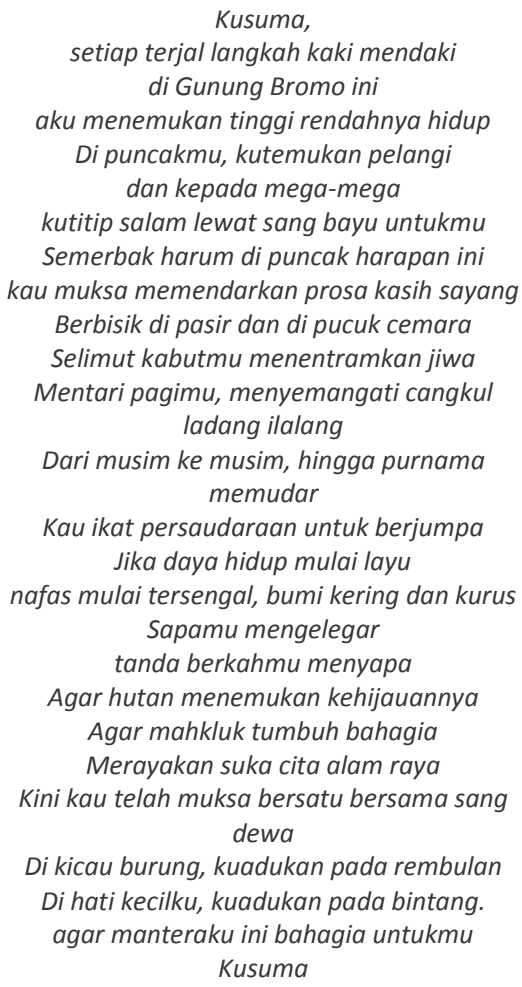

Gambar 6. (1) Puisi Kidung Tengger; (2) Penerapan enam bait puisi kedalam rancangan Sumber: (1) Heri Lentho, 2017; (2) Penulis, 2021

Dari puisi Kidung Tengger kemudian diterjemahkan setiap baitnya untuk diterapkan kedalam rancangan. Setiap bait juga dihubungkan dengan unsur perasaan untuk menghadirkan unsur fenomenologi kedalam rancangan. Secara keseluruhan puisi memiliki enam bait dan diterjemahkan berupa: 1) The Misery; 2) The Sacrifice; 3) The Peace; 4) The Ritual; 5) The Calling; 6) The Memory (Tabel 2).

Tabel 2. Terjemahan bait puisi dan penerapan desain

\begin{tabular}{|c|c|c|c|c|}
\hline Bait & Unsur & Setting Awal & Makna & Penerapan Desain \\
\hline $\begin{array}{l}\text { Bait 1: } \\
\text { The } \\
\text { Misery }\end{array}$ & $\begin{array}{c}\text { Cerminkan } \\
\text { diri }\end{array}$ & $\begin{array}{c}\text { Gunung Bromo yang } \\
\text { meliputi awan kegelapan } \\
\text { dan meletus tanpa henti } \\
\text { tanda meminta janji pada } \\
\text { Raden Kusuma }\end{array}$ & $\begin{array}{l}\text { Merepresentasikan } \\
\text { kesulitan Suku } \\
\text { Tengegr sebelum } \\
\text { pengorbanan Raden } \\
\text { Kusuma }\end{array}$ & $\begin{array}{c}\text { Menciptakan lorong } \\
\text { gelap dengan } \\
\text { lubang cahaya }\end{array}$ \\
\hline $\begin{array}{l}\text { Bait 2: } \\
\text { The } \\
\text { Sacrifice }\end{array}$ & Kesedihan & $\begin{array}{c}\text { Di waktu pengorbanan } \\
\text { Raden Kusuma, seluruh } \\
\text { Suku Tengger berkumpul } \\
\text { untuk sukacita dan } \\
\text { hormat kepada Raden } \\
\text { Kusuma }\end{array}$ & $\begin{array}{c}\text { Merasakan sesaat } \\
\text { pengorbanan Raden } \\
\text { Kusuma terjadi }\end{array}$ & $\begin{array}{l}\text { Plataran yang } \\
\text { dikeliligi void untuk } \\
\text { merasakan kesan } \\
\text { saat pengorbanan di } \\
\text { kawah gunung }\end{array}$ \\
\hline
\end{tabular}




\begin{tabular}{|c|c|c|c|c|}
\hline $\begin{array}{l}\text { Bait 3: } \\
\text { The } \\
\text { Peace }\end{array}$ & Bersyukur & $\begin{array}{l}\text { Keindahan yang dirasakan } \\
\text { setelah pengorbanan } \\
\text { Raden Kusuma seperti } \\
\text { hamparan bunga, pasir, } \\
\text { kabut, matahari }\end{array}$ & $\begin{array}{c}\text { Sukacita dan } \\
\text { keindahan alam atas } \\
\text { pengorbanan Raden } \\
\text { Kusuma }\end{array}$ & $\begin{array}{c}\text { Plataran Bromo dan } \\
\text { matahari untuk } \\
\text { menikmati } \\
\text { pemandangan }\end{array}$ \\
\hline $\begin{array}{l}\text { Bait 4: } \\
\text { The } \\
\text { Ritual }\end{array}$ & Sakral & $\begin{array}{l}\text { Ritual dan upacara yang } \\
\text { dilakukan keturunan Suku } \\
\text { Tengger sebagai bentuk } \\
\text { rasa syukur }\end{array}$ & $\begin{array}{c}\text { Ucapan dan rasa } \\
\text { terima kasih serta } \\
\text { syukur atas } \\
\text { pengorbanan Raden } \\
\text { Kusuma }\end{array}$ & $\begin{array}{c}\text { Jembatan yang } \\
\text { dipisahkan air } \\
\text { menjadi tanda } \\
\text { perjalanan } \\
\text { pensucian Raden } \\
\text { Kusuma } \\
\end{array}$ \\
\hline $\begin{array}{l}\text { Bait 5: } \\
\text { The } \\
\text { Caling }\end{array}$ & Kesadaran & \multirow{2}{*}{$\begin{array}{l}\text { Suku Tengger hidup } \\
\text { dalam pesembunyian } \\
\text { akibat Gunung Bromo } \\
\text { yang terus meletus } \\
\text { merusak lingkungan } \\
\text { sekitar sebelum } \\
\text { pengorbanan Raden } \\
\text { Kusuma. }\end{array}$} & $\begin{array}{c}\text { Agar Suku Tengger } \\
\text { senantiasa selalu } \\
\text { menjaga alam }\end{array}$ & \multirow{2}{*}{$\begin{array}{l}\text { Ruangan bawah } \\
\text { tanah sebagai } \\
\text { memori Suku } \\
\text { tengger akan } \\
\text { persembunyian }\end{array}$} \\
\hline $\begin{array}{l}\text { Bait 6: } \\
\text { The } \\
\text { Memory }\end{array}$ & Menghormati & & $\begin{array}{l}\text { Mengenang Raden } \\
\text { Kusuma agar Suku } \\
\text { Tengger tetap pada } \\
\text { jati dirinya }\end{array}$ & \\
\hline
\end{tabular}

Sumber: Penulis, 2021

Perancangan juga menerapkan paramater beyond ecology sesuai dengan tema perancangan, meliputi beberapa parameter yaitu: 1) Adaptation, beradaptasi dengan lingkungan saat gunung berapi meletus, 2) Resilience, dapat bertahan saat bencana terjadi dan juga sebagai tempat perlindungan, 3) Sustainable, mempertahankan area penghijauan yang dominan dan memanfaatkan kondisi topografi, 4) New Technology, pemanfaatan energi geothermal, 5) Context, menerapkan budaya dan tradisi asli Suku Tengger (Gambar 7).

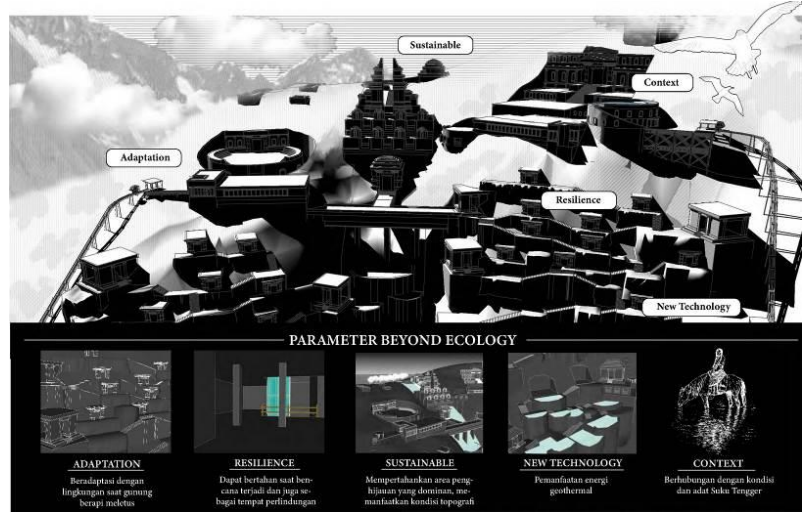

Gambar 7. Diagram Beyond Ecology

Sumber: Penulis, 2021

\section{Hasil Produk Perancangan}

Hasil produk rancangan adalah hasil dari pengumpulan data, analisis tapak, analisis program, serta penerapan konsep dan metode. Hasil dari analisis tapak digabungkan dengan penerapan pembagian bait dari puisi Kidung Tengger yang selanjutnya dimasukkan unsur arsitektur Majapahit kedalam rancangan. Secara keseluruhan, bangunan terbagi atas tiga zona, yaitu zona kiri yang memiliki akses langsung dengan viewpoint penanjakan yang diperuntukkan untuk wisatawan, zona kanan memiliki akses dari jalan yang diperuntukkan untuk pelaksanaan upacara adat Suku Tengger dan zona tengah sebagai penguat antara kedua zona. Zona tengah memiliki arah aksis langsung ke Gunung Bromo dan Gunung Semeru sehingga diletakkan monumental candi Wringin Lawang yang menghadap langsung ke aksis Gunung sesuai dengan arsitektur Majapahit. Ketiga zona memiliki plataran masing-masing sebagai unsur Majapahit yang kuat 
(Gambar 8). Ketiga plataran tersebut yaitu: 1) Plataran Bromo di zona kiri untuk memandang Gunung Bromo dan matahari terbit; 2) Plataran upacara di zona kanan untuk melakukan berbagai upacara maupun pentas adat; 3) Plataran Edelweis di zona tengah sebagai area untuk menikmati bunga Edelweis.

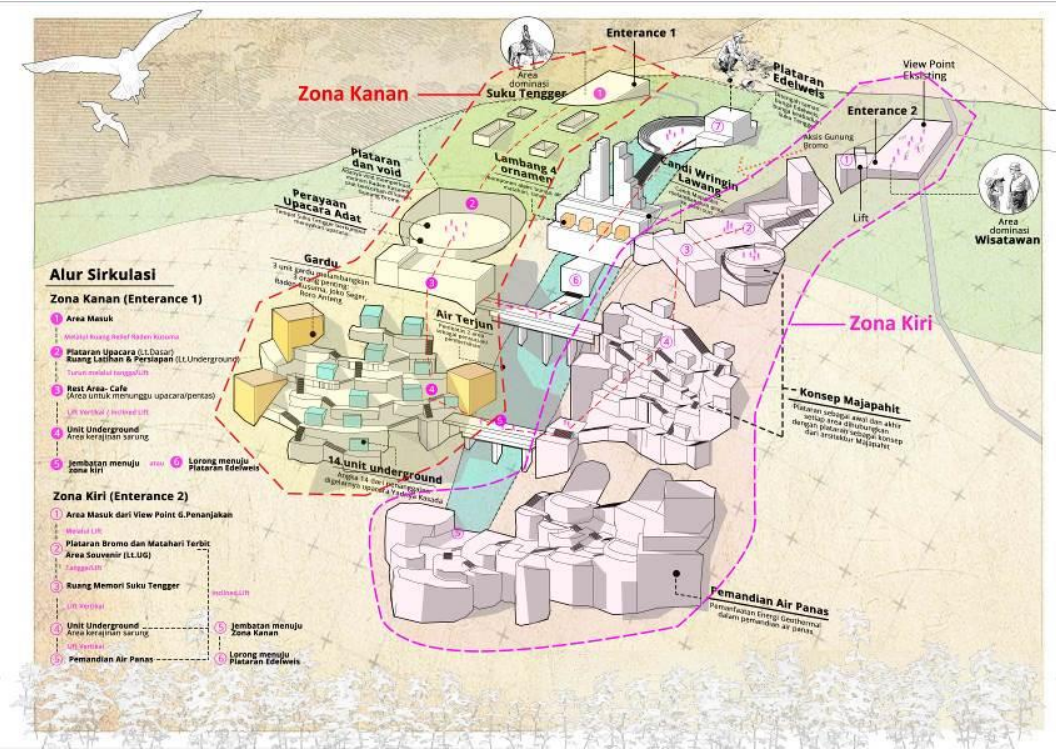

Gambar 8. Skema Desain menjelaskan sirkulasi dan pembagian zona massa bangunan Sumber: Penulis, 2021

Dengan kondisi kontur yang curam lebih dari $45^{\circ}$, beberapa bangunan dibuat dibawah tanah. Di sisi tebing memiliki ruang bawah tanah yang dapat diakses dari dalam maupun luar. Tebing dan ruang bawah tanah dikaitkan dengan legenda Suku Tengger yang bersembunyi di gunung penanjakan akibat letusan Gunung Bromo. Tebing juga merupakan representasi kondisi kehidupan Suku Tengger yang terbiasa untuk menanjak karena kehidupannya di lereng-lereng Gunung Bromo. Ruang-ruang bawah tanah juga dapat digunakan sebagai perlindungan dikala Gunung Bromo meletus.

Jumlah ruang bawah tanah setiap sisinya berjumlah 11 unit, dan ditambahkan dengan gardu sebanyak tiga buah sehingga total 14 ruang yang menandakan hari ke-14 penanggalan bulan kasada untuk melakukan upacara Yadnya Kasada, upacara keagamaan bagi Suku Tengger sedangkan tiga gardu menandakan tiga orang penting di Suku Tengger yaitu Jaka Seger, Rara Anteng, dan Raden Kusuma. Jumlah seluruhnya adalah 22 unit ruang bawah tanah dan 6 gardu utama. Pemandian air panas memiliki 2 unit bawah tanah yang merupakan penghubung antar ruang. Dari area masuk menuju unit bawah tanah disediakan dua akses yaitu akses melalui lift vertikal dan lift miring. Lift vertikal terhubung dengan setiap ruang (Gambar 9), sedangkan lift miring memiliki 3 terminal zona kiri dan 2 terminal zona kanan. Lift terbuat dari kaca sehingga pengunjung dapat menikmati pemandangan alam secara maksimal. 


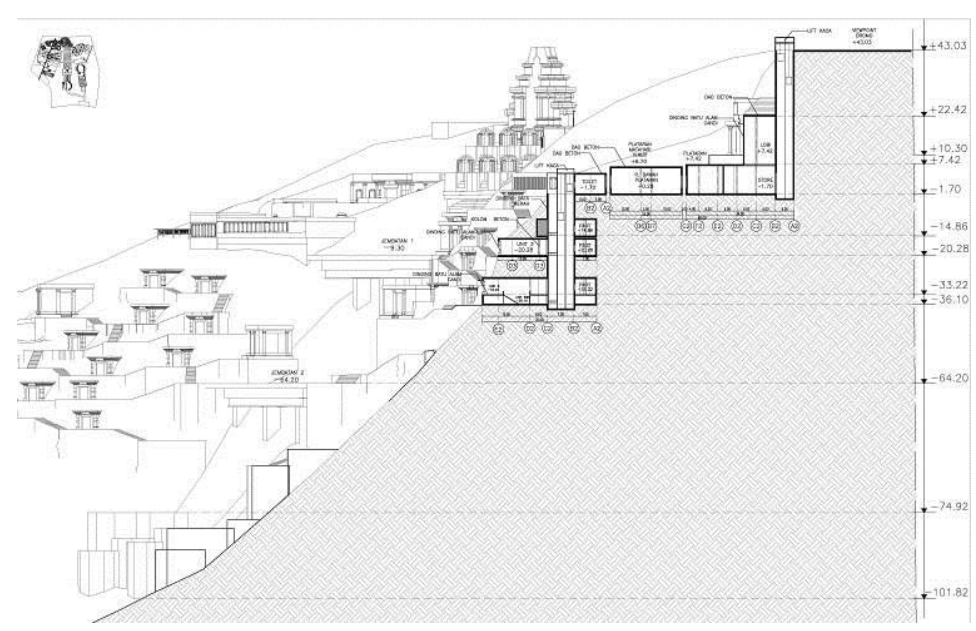

Gambar 9. Potongan bangunan memperlihatkan kondisi tebing yang dihubungkan dengan lift dan menciptakan panorama komposisi bangunan dibelakangnya

Sumber: Penulis, 2021

Struktur bangunan yang digunakan adalah kolom dan balok, dengan penggunaan retaining wall disetiap sisi yang bersinggungan dengan bebatuan dalam. Pada terminal lift, material yang digunakan rangka baja untuk membedakan area modern dan tradisional. Dinding bangunan dibuat penebalan agar sesuai dengan konsep Majapahit serta penambahan ukiran dan ornamen pada dinding. Material bangunan tetap berhubungan dengan konsep majapahit yaitu dengan menggunakan batu bata candi dan batu bata merah untuk sebagian besar bangunan (Gambar 10).

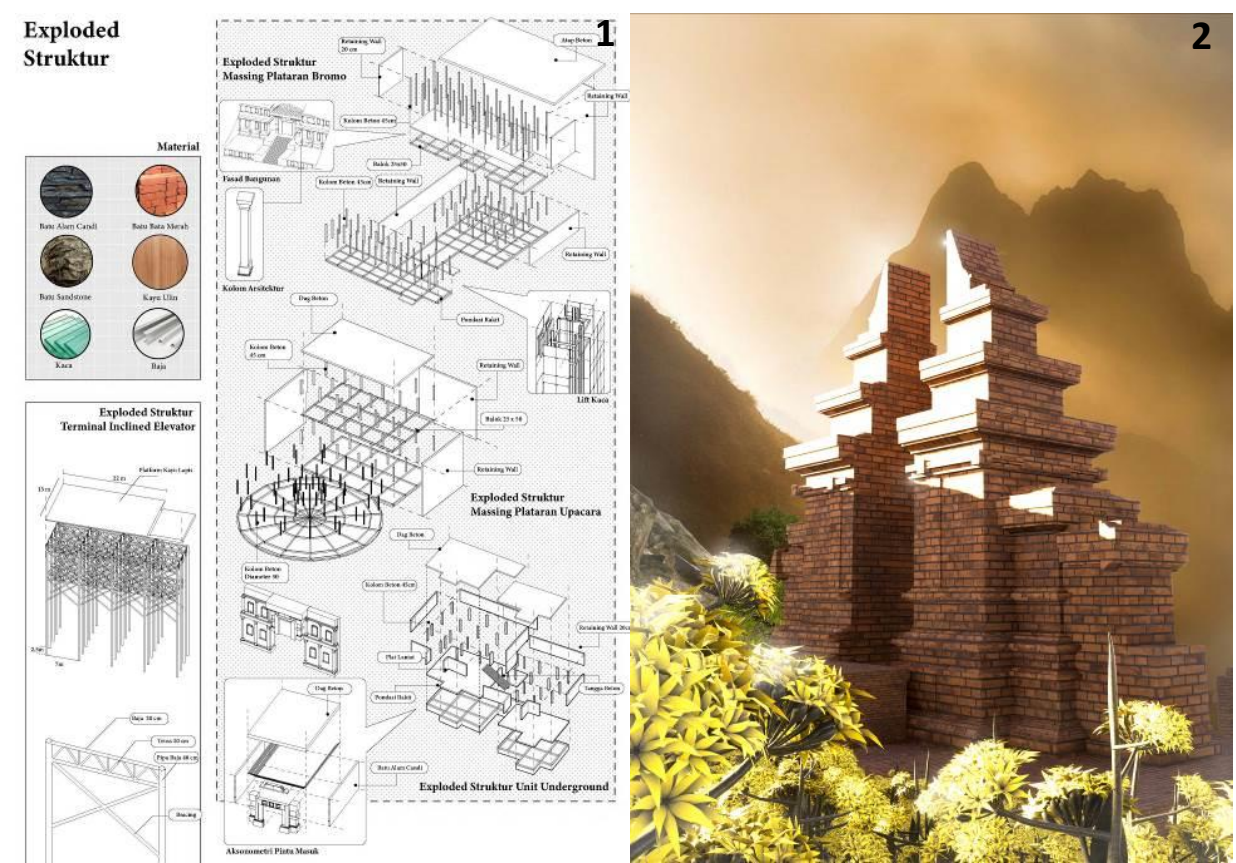

Gambar 10. (1) Struktur kolom dan balok pada bangunan dan baja pada terminal lift miring;

(2) Penggunaan material batu bata merah pada bangunan candi.

Sumber: Penulis, 2021

Walaupun memiliki banyak bangunan yang berada di bawah tanah, ruang-ruang tetap mendapatkan penghawaan dan pencahayaan alami. Disediakan beberapa titik void yang digunakan juga untuk penempatan lift dan mendapatkan aliran udara melalui bukaan di sisi lainnya sehingga hampir di semua ruang mendapat cross ventilation (Gambar 11). 


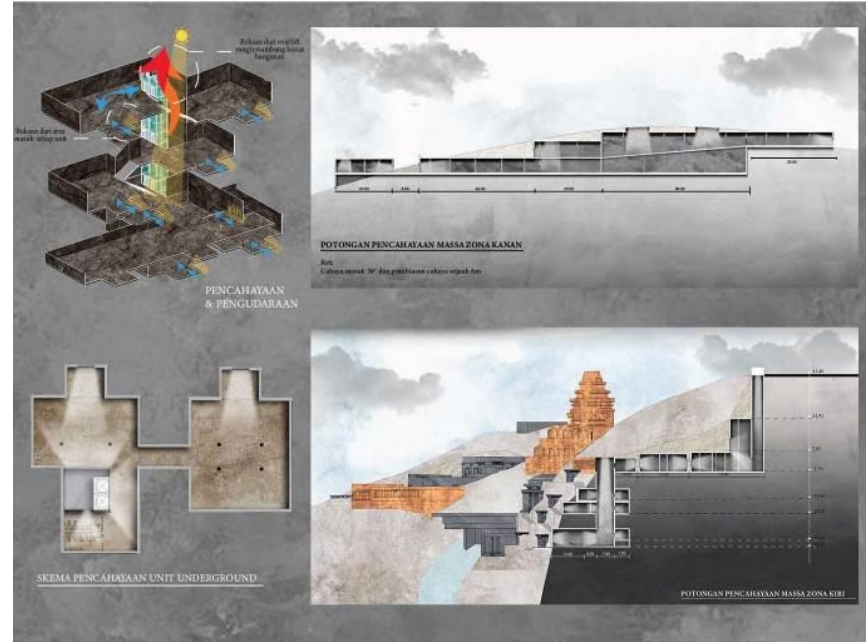

Gambar 11. Potongan yang menunjukkan lubang cahaya untuk pencahayaan maupun pengudaraan Sumber: Penulis, 2021

Proyek diperkuat dengan kelengkapan unsur-unsur alam beserta kondisi ekologi yang ada di sekitar lokasi tapak (Gambar 12). Salah satunya kehadiran Gunung Bromo sebagai bagian dari alam menjadi patokan yang kuat untuk proyek. Selain Gunung Bromo, beberapa unsur alam yang semakin menguatkan proyek antara lain matahari terbit dan terbenam karena letaknya di ketinggian, dinginnya kabut, hamparan bunga Edelweis, lautan pasir yang mendukung panorama proyek, air terjun, serta bebatuan pegunungan yang menjadi dasar dalam perancangan. Hadirnya unsur-unsur alam tersebut yang digabungkan dengan unsur-unsur budaya setelah diterjemahkan kedalam perancangan membuat proyek sesuai dengan persoalan yang dihadapi sekaligus melengkapi ekologi Suku Tengger.

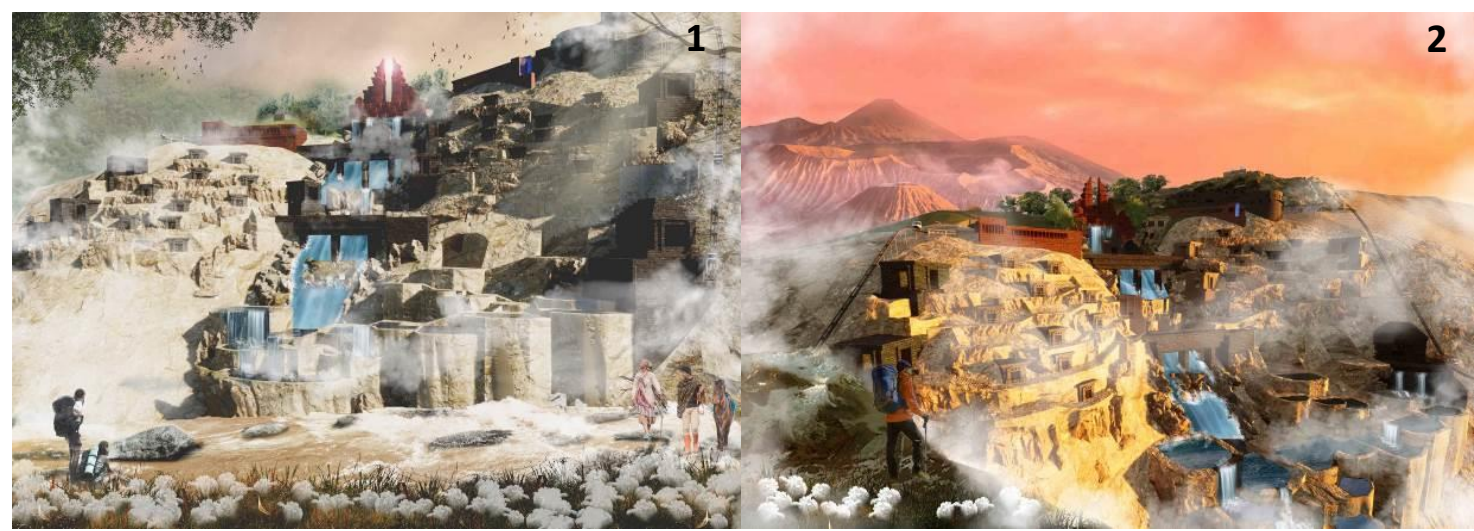

Gambar 12: (1) Perspektif mata manusia, menampilkan kolase proyek beserta hamparan lautan pasir dan bunga edelweis; (2) Pespektif mata burung, menampilkan kolase proyek dengan pemandangan alam bromo dalam langit matahari terbenam

Sumber: Penulis, 2021

\section{KESIMPULAN DAN SARAN Kesimpulan}

Semerbak Harum Sang Kusuma adalah desain arsitektur yang dapat membantu menguatkan budaya Suku Tengger dalam menghadapi perkembangan modernisasi. Dengan memasukkan unsur-unsur budaya yang dituangkan dalam penerapan puisi Kidung Tengger, dapat memunculkan kembali kenangan dan perasaan jati diri akan pentingnya budaya yang mereka 
punya. Tetapi juga tidak menutup mata terhadap perkembangan modern seperti pemakaian teknologi dan material modern.

Hasil dari proyek ini menciptakan ruang-ruang yang merupakan representasi setiap bait puisi Kidung Tengger yang memiliki makna budaya yang sangat dalam serta kegiatan-kegiatan yang tentunya mendukung budaya seperti kerajinan sarung, taman bunga Edelweis, plataran pemandian air panas, dan ruang memori Suku Tengger. Setiap bagian ruang memiliki makna tertentu yang membangkitkan semangat budaya asli Suku Tengger. Tidak hanya budaya secara tradisional, penggunaan teknologi seperti lift dan energi, diterapkan sebagai bentuk modernisasi. Sehingga kedua budaya yaitu tradisional dan modern tetap dapat berjalan beriringan dengan memanfaatkan keuntungan masing-masing untuk Suku Tengger sehingga mencapai keseimbangan ekologi untuk kehidupan mereka. Proyek Semerbak Harum ini diharapkan dapat membuka kemungkinan untuk digunakan sebagai dasar pengembangan proyek-proyek pelestarian budaya suatu kelompok tertentu.

\section{Saran}

Penelitian-penelitian yang menampilkan budaya asli dapat mengedukasi masyarakat dalam mengetahui seberapa pentingnya hubungan suatu budaya dengan alam yang berkaitan. Diharapkan dengan adanya penelitian-penelitian yang bersifat memperkenalkan budaya asli dan pengaruhnya terhadap keseimbangan ekologi ini semakin dikenal sehingga budaya-budaya asli tersebut semakin kuat dan tidak mudah terlupakan dalam menghadapi berbagai tantangan budaya baru.

\section{REFERENSI}

Adam, A. F., \& Liana, C. (2020). Upacara Adat Yadnya Kasada Kecamatan Tosari Kabupaten Pasuruan. AVATARA, 10.

BP86. (2010, November 24). Peta Kawasan Rawan Bencana Gunung Bromo. Retrieved from GIS Indonesia: http://inigis.com/peta-kawasan-rawan-bencana-gunung-bromo/

Frampton, K. (1983). Towards a Critical Regionalism: Six Points for an Architecture of Resistance.

Haliim, W. (2018). Harmony and Tolerance as a Tengger Identity: Reflections for Indonesian Identity and Unity Degradation. International Journal of Social Science, 1-8.

Hikmah, K., Sazhiyah, S. R., \& Sulistyowati, T. (2020). Dinamika Kehidupan Masyarakat Suku Tengger Dibalik Kegiatan Parawisata Bromo. Journal of Tourism and Creativity, 105-116.

Koetjaraningrat. (2005). Pengantar Antropologi II. Jakarta: Rineka Cipta.

Prayogi, R., \& Danial, E. (2016). Pergeseran Nilai-Nilai Budaya Pada Suku Bonai Sebagai Civic Culture di Kecamatan Bonai Darussalam Kabupaten Rokan Hulu Provinsi Riau. HUMANIKA, 23, 74-75.

Putra, A. S. (2018). Pesona Gunung Bromo Sebagai Wisata Unggulan Di Pasuruan, Jawa Timur. Yogyakarta: Domestic Case Study 2018, Sekolah Tinggi Parawisata Ambarrukmo Yogyakarta.

Ranjabar, J. (2006). Sistem Sosial Budaya Indonesia . Bogor: Ghalia Indonesia. 